\title{
O Usucapião e o imposto de transmissão de bens imóveis
}

Controvertida é a questão de saber se, em face do atual sistema tributário brasileiro, o usucapião é fato gerador do imposto de transmissão de bens imóveis.

O Código Tributário Nacional tornou expresso e imperativo pa ra as leis tributárias ordinárias federais, estaduais e municipais, o seguinte princípio que se encontra em seu artigo 110, no capítulo concernente à interpretação e à integração da legislação tributária:

"Art. 110. A lei tributária não pode alterar a definição, o conteúdo e 0 alcance de institutos, conceitos e formas de direito privado, utilizados, expressa ou implicitamente, pela Constituição Federal, pelas Leis Orgânicas do Distrito Federal ou dos Municípios, para definir ou limitar competências tributárias".

Essa norma proíbe a lei tributária ordinária de, na configuração do fato gerador do tributo por ela instituido, a apartar-se da definição, do conteúdo e do alcance de institutos, conceitos e formas de direito privado de que se tenha utilizado a Constituição Federal para definir ou limitar competência tributária.

Ora, a definição da competência tributária dos Estadosmembros e dos municípios - que é exclusivamente a expressa na Constituição Federal, uma vez que ambos, ao contrário do que ocorre com a União, não dispõem de competência residual $\left(\S 1^{\circ}\right.$. do artigo 21 da Emenda Constitucional n. 1/69) - se estabelece, no tocante a impostos, pela caracterização do fato gerador deles.

Em se tratando de imposto de transmissão de imóveis, reza o artigo 23̦, I, da Constituição Federal:

"Art. 23. Compete aos Estados e ao Distrito Federal instituir impostos sobre:

1 - transmissão, a qualquer título, de bens imóveis por nature- 
za e acessão física e de direitos reais sobre imóveis, exceto os de garantia, bem como a cessão de direitos à sua aquisição;

"Transmissão, a qualquer título, de bens imóveis por natureza e acessão física e de direitos reais sobre imóveis, exceto os de garantia" são expressões constitucionais que exprimem - e quanto a isso ninguém o nega - a transmissão, a qualquer título, do direito de propriedade ou de direito real limitado, que não os de garantia, sobre imóveis por natureza ou por acessão física.

Transmissão de propriedade ou transmissão de direitos reais limitados sobre imóveis é, inquestionavelmente, conceito de direito privado, de que a Constituição Federal se valeu, expressamente para definir competência tributária dos Estados-membros.

$E$, conseqüentemente, em face do princípio imperativo do artigo 110 do Código Tributário Nacional, é conceito cujo conteúdo e alcance são exclusivamente os fixados pelo direito privado. De feito, esse artigo 110 afastou, no tocante às definições e às limitações de competência tributária, a denominada interpretação econômica, que mesmo os tributaristas brasileiros que a acolhiam, anteriormente à promulgação do Código Tributário Nacional - assim, entre outros, Amilcar Falcão (Fato Gerador da Obrigação Tributária, 1.ed. n. 19, p. 71 e segs., 4. ed. - que reproduz a 1. ed. - , São Paulo, Revista dos Tribunais, 1977); e Ruy Barbosa Nogueira (Da interpretação e da Aplicação das Leis Tributárias, n. 109/111, p. 85-87, São Paulo, Revista dos Tribunais, 1963). A propósito, escrevia Amilcar Falcão, ob. cit., n. 19, p. 75:

"É evidente que a interpretação econômica só se admitirá, em cada caso concreto, para corrigir situações anormais artificiosamente criadas pelo contribuinte. Por outras palavras, através dela não se pode chegar ao resultado de, na generalidade dos casos, alterar ou modificar, por considerações subjetivas que o intérprete ou o aplicador desenvolvam no que respeita à justiça fiscal, um conceito adotado, pelo legislador. É a isso que se faz alusão, quando se assevera que a interpretação econômica não pode ter o efeito de uma interpretação abrogans.

Se, verbi gratia, o legislador tributou empréstimos e isentou vendas, por exemplo, não se toleraria que, por meio de interpretação econômica, o exegeta concluísse que, nas vendas a prestação, a relação econômica é semelhante à que se configura através do empréstimo, para, na generalidade dos casos, concluir pela exclusão destas do conceito de venda e seu enquadramento na incidência prevista quanto aos empréstimos.

O que em tal hipótese ocorreria fora, não uma interpretação da lei, mas uma emendatio legis, uma alteração do seu comando, uma interpretatio abrogans, à luz de considerações políticas eminentemente subjetivas, que o intérprete desenvolvesse em matéria de justiça fiscal, coisa que não é consentida".

E, em obra anterior (escrita em 1959), Introdução ao Direito 
Tributário, Parte Geral, n. 10, p. 137-8, Rio de Janeiro, Edições Financeiras, Amilcar Falcão assim examinava o problema, no concernente à discriminação constitucional de competência tributária:

"O sistema de discriminação rígida de rendas, entretanto, vem trazer uma restrição à autonomia local, no particular.

Procurando-se, por esse sistema, segregar as diferentes competências tributárias da federação e dos governos periféricos, resulta evidente que o objetivo constitucional foi evitar concorrência sobre os tributos discriminados.

Para que isso se concretize, mister se fará que a interpretação dos preceitos constitucionais relativos à partilha da competência tributária seja estrita, sob pena de inutilizar-se ou tumultuar-se a própria distribuição de rendas.

Não poderão os governos locais, quer normativamente, quer pela via da aplicação, exercitar uma interpretação em matéria tributária que, embora seja legítima dentro daquele esquema da chamada wirtschaftliche Betracharchtungsweise, venha acarretar uma deslocação da implantação constitucional do tributo, tal como rigidamente fixava no texto constitucional.

A matéria, efetivamente, tem suscitado discussão, havendo os que sustentam a opinião oposta como sendo a única que se compatibiliza com o regime federativo e os que sustentam a tese por nós acoIhida e que, aliás, é a predominante no direito brasileiro".

Essa tese, que Amilcar Falcão, em nota (nota 22, p. 138), lembrava ser a do Supremo Tribunal Federal que, com base nela, declarara a inconstitucionalidade da extensão do imposto de transmissão inter vivos às cessões de promessa de venda de imóveis, hoje não é mais tese doutrinária ou jurisprudencial, mas imposta por texto expresso de lei, o artigo 110 do Código Tributário Nacional.

Por isso, para saber-se se no usucapião há, ou não, transmissão, a qualquer título, de imóvel ou de direitos reais sobre imóvel, exceto os de garantia (inciso I do artigo 23 da Constituição Federal) , mister se faz verificar se o que significa, no direito privado, o conceito de transmissão de direito de propriedade ou de direito real limitado, a fim de determinar-se o seu alcance.

E é o que passo a fazer.

Com muita acuidade, observou Von Thur (Der Allgemeine Teil des Deutschen Bürgerlichen Rechts, erster Band, I, § 12, p. 219-20, Leipzig, 1910), ao estudar a transmissibilidade dos direitos. que o conceito de transferência do direito não é produto de uma necessidade lógica, mas o resultado do desenvolvimento histórico do pensamento dogmático; seu ponto de partida foi a transmissão da propriedade: "quando alguém domina a mesma coisa da mesma maneira pela qual outrem a dominava antes dele, e deve a este outro seu senhorio, já o pensamento jurídico ingênuo está, em certa medida, forçado a aceitar a identidade do direito por meio da identidade do objeto sob dominação" ("Daher ist der Begriff des Rechtsüberganges kein Produkt logischer Notwendigkeit, sondern das Resultat der historischen Ent- 
wicklung des dogmatischen Denkens; der Ausgangspunkt ist die Eigentumsübertragung gewesen: wenn Jemand dieselbe Sache in derselbem Weise behercht, wie vor ihm ein Anderer, und seine Herrschaft diesem Anderer verdankt, wird die Annahme einer ldentität des Rechts schon dem naiven juristischen Denken durch die Identität des beherrschten Objekts gewissermassen aufgedrängt" ).

Sendo o conceito de transmissão do direito - inclusive o de transmissão do direito de propriedade - o resultado do desenvolvimento histórico do pensamento dogmático, sua elaboração não se fez sem controvérsias, de um único jato, mas decorreu de um processo lento, em cujo decurso muitos equívocos foram afastados.

Neste terreno, especialmente, os equívocos se justificavam pela circunstância de que os textos romanos são imprecisos, pois a própria concepção de sucessão (successio) se alterou profundamente entre o direito clássico e o direito justinianeu.

O que importa, portanto, é determinar qual o conceito de transmissão da propriedade a que chegou a dogmática moderna.

Os autores modernos observam que, logicamente, não se confundem transmissão, sucessão e aquisição de direitos. Em notável estudo sobre a transferência do direito, Pugliatti (Esecuzione Forzata e Diritto Sostanziale, p. 87 e segs., Milano, 1935), depois de acentuar que a aquisição do direito é apenas um dos dois efeitos de sua transmissão, salienta que esta se caracteriza porque produz uma perda em relação ao titular precedente e uma aquisição com referência ao novo titular, sendo estes dois efeitos interdependentes, contemporâneos e, sobretudo, baseados na mesma causa jurídica ("II transferimento produce una perdita in capo al titolare precedente e un acquisto in capo al nuovo titolare. Questidue effettiperó sono interdipendenti, contemporanei e sopratutto basati sulla medesima causa giuridica", $p$. 98). E acrescenta que não decorrem de transmissão as aquisições que, embora sucessivas a uma perda, dependem de causa autônoma, como sucede quando, em seguida ao abandono de uma coisa (derelictio), alguém adquire a propriedade sobre ela pela ocupação, caso em que não ocorre transmissão de direito porque o abandono e a ocupação são dois atos jurídicos distintos e independentes. Por outro lado, observa Pugliatti (p. 103 e segs.) que a sucessão em sentido amplo abarca a transmissão, pois compreende, em seu seio, as aquisições derivadas, mas a sucessão em sentido estrito, em rigor, não se confunde com a transmissão, pois são conceitos que têm pontos de partida diversos:

"... nel transferimento il punto dipartenza è il primo titolares del diritto; nella successione il punto di partenza è il soggestto che aquista. Vero è che anche nel transferimento abbiamo um acquirente e, se vuolsi, un successore, ma il transferimento muove dal transmittente al quale fa capo la forza propulsiva che lo opera."

O que é certo, porém, é que - ao contrário do que sucedia no direito romano clássico, em que transmissão e sucessão eram conceitos substancialmente diversos - no direito moderno as duas expressões, que formalmente se prendem a elos diversos da mesma cadeia 
(a transmissão ao transmitente e a sucessão ao adquirente), substancialmente designam o miesmo fenômeno global, como bem acentua Galvão Teles (Algumas considerações sobre o conceito juridico de sucessão, n. 7, p. 43, Lisboa, 1965):

"Os termos transmissão e sucessão podem hoje considerar-se sinônimos. Designam o fenômeno global que resulta da perda ou liberação relativas e da aquisição ou vinculação derivadas. $\mathrm{O}$ direito ou obrigação deixa de ter um sujeito, de que se desprende, e passa a ter outro, em que se radica. A relação jurídica transmite-se, pelo lado ativo ou passivo, ou, o que é o mesmo, uma pessoa sucede a outra na sua titularidade".

Por outro lado, de toda transmissão (ou sucessão) de direito resulta a aquisição deste. Mas a recíproca não é verdadeira: há direitos que se adquirem sem ser por meio de sucessão ou transmissão, como, por exemplo, ocorre na ocupação.

Foi com base nessa observação que a Escola do Direito Natural introduziu na dogmática jurídica uma distinção que era desconhecida dos romanos: a aquisição de um direito pode ser originária ou derivada. E, como se vê em Grócio (Le Droit de la Guerre et de la Paix, trad. P. Pradier-Fodéré, t. I e II, p. 431 e segs. e p. 1 e segs., respectivamente, Paris, 1867), essa distinção tomou por base, essencialmente, a ocupação de res nullius ou de res derelictae para a aquisição originária, e a traditio e a sucessão hereditária (testamentária ou legítima) para a aquisição derivada.

A doutrina moderna, em geral, adotou como critério para distínguir a aquisição originária da aquisição derivada de direitos a existência, ou não, de sucessão (tida como sinônima de transmissão). Portanto, encarou a distinção pelo seu lado subjetivo (que é o que diz respeito à sucessão ou transmissão de direitos) e não pelo seu aspecto objetivo (que é o que concerne ao nascimento, modificação e extinção das relações jurídicas em si mesmas). E, por haver tomado como critério dessa distinção o conceito de sucessão ou transmissão, salientou a doutrina moderna que a importância dela se explicava pelo fato de, na aquisição originária - ao contrário do que ocorria na aquisição derivada - , não se aplicavam as duas seguintes regras jurídicas:

a) - nemo ad alium transfere potest plus iuris quam ipse habet (ninguém pode transferir mais direitos do que tem); e

b) - resoluto iure concedentis, resolvitur ius concessum (resolvido o direito do concedente, resolve-se o direito do concedido).

Essas regras, como é intuitivo, pressupõem a vinculação, por força da vontade ou da lei, entre o titular anterior lo transmitente, o causam dans) e o novo titular (o adquirente, o causam habens. Por isso, a doutrina moderna conceituou essas duas modalidades de aquisição com expressões que caracterizam a existência, ou não, de relacão entre transmitente e adquirente. Assim, por exemplo, diz Betti (Istituzioni di Diritto Romano, v. 1, ristampa della $2^{2}$ edizione, § 47 , p. 84-5), que "è derivativo l'acquisto se è giustificato da un rapporto dell'acquirente con altra persona determinata che sia legittimata a dis- 
porre in ordine alla cosa del cui acquisto si tratta è originario se è giustificato da un rapporto immediato con la cosa del cui acquisto si tratta, senza il tramite di altra persona". Ou, como preleciona Coviello (Manualle di Diritto Civile Italiano, Parte Generale, § 98, p.311-2):

"La distinzione tra acquisto originario e acquisto derivativo si fonda sulla mancanza o l'esistenza d'un rapporto personale tra un precedente e un sussequente soggestto del diritto. Se il rapporto tra le due persone manca, l'acquisto è originario sia che il diritto preesista, come nel caso di occupazione di cosa abbandonata, sia che il diritto sorga per la prima volta, come nell'ocupazione di res nullius. Invece è derivativo, quando la persona che acquista il diritto si fonda sul diritto del precedente titolare che ne forma il pressuposto, dimodo chél'esistenza, l'estensione e le qualità del diritto acquistato vengono valutate alla stregua del diritto precedente che ne è fondamento: esempio tipico d'acquisto derivativo è quello per contratto o per successione causa mortis. L'acquisto è derivativo non solo se siacquista lo stesso diritto preesistente in altri (come accade nell'acquisto della proprietà), ma anche se siacquista un diritto nuovo che precedentemente non aveva esistenza a sè, ma che pressuppone l'esistenza di altro diritto su cui fonda (come nel caso dell'acquisto di servitù per contratto). La persona sul cui diritto si fonda il diritto acquistato si chiama autores, dante causa: quella che ha acquistato si chiama avente causa o anche successore)."

Como se vê, a doutrina moderna distinguiu a aquisição originária da aquisição derivada de direitos com base no critério da existência, ou não, de transmissão ou sucessão, conceitos esses que, juridicamente, exprimem uma relação de causalidade entre o transmitente (causam dans) e o adquirente (causam habens).

Sucede, porém, que - como é comum ocorrer na ciência jurídica moderna - há sempre algum jurista que pretende inovar, e, para fazê-lo, o método empregado é o de encarar o mesmo fenômeno jurídico sob outro ângulo, o que, em linguagem jurídica, se traduz, em geral, pelas expressões "outro critério".

Foi o que fez Brinz la princípio, em artigo - Possessionis traditio - publicado, em 1859, v. III, p. 16 e segs., do Jahrbuch des gemeinen deutschen Rechts; e, depois, no Lehrbuch der Pandekten, erster Band, 2. ed., $\S \S 76$, II, e 153, p. 244-5 e 595), ao examinar se o usucapião seria modo originário ou derivado de aquisição da propriedade. Para sustentar - o que toda doutrina repelia com base no fato de que a distinção dessas formas de aquisição se baseava no critério da transmissão ou sucessão, sendo que a aquisição derivada só ocorria quando havia transmissão ou sucessão, o que inexistia no usucapião - que o usucapião era modo derivado de aquisição, e não modo originário, Brinz modificou o critério em que se baseava a própria distinção entre essas duas formas de aquisição. Deixou ele de lado o critério da sucessão ou da transmissão, e caracterizou a diferença entre aquisição originária e aquisição derivada com base em critério objetivo (e, portanto, desvinculado da idéia de sucessão ou transmissão que se prende aos titulares do direito - critério subjetivol. Esse critério objetivo consistia em considerar que só havia aquisição originária 
quando o direito de propriedade não preexistisse à sua aquisição, ao passo que a aquisição derivada ocorreria na hipótese de o direito de propriedade haver preexistido, ainda que não houvesse qualquer vinculação entre transmitente e adquirente. Esse critério, para Brinz, se impunha pelo fato de que, ainda quando não houvesse vinculação entre transmitente e adquirente, o direito de propriedade que surgia posteriormente continuava onerado pelos mesmos ônus reais que havia quando ele estava sob a titularidade do proprietário anterior. Deixava-se de lado o critério da sucessão ou transmissão (critério subjetivo), para adotar-se critério diverso (critério objetivo).

Perozzi, em nota à tradução italiana do volume que Czihlarz escreveu em continuação ao comentário às Pandectas de Glück (Commentario Alle Pandette, libro XLI, nota 1, p. 29-30), percebeu, de maneira precisa, a divergência que se estabelecia entre a doutrina tradicional e a proposta por Brinz. Ela decorria da mudança do critério em que se baseava a distinção entre aquisição originária e aquisição derivada:

"Bisognava che il Brinz, lasciata cadere la distinzione tra fondazione di proprietà nuvo o trasmissione di proprietà antica, facesse la distinzione tra modioriginarie derivativi, com'io ho detto; oppure che fatta la distinzione cosiprendesse il fatto che ipesi inerentialla proprietà antica continuano o cessano come critério per dire, che la proprietà acquistata è sempre la vecchia, oppure à nuova",

e, logo abaixo, ainda se referindo aos modos de aquisição em face desses dois critérios (o subjetivo, vinculado ao conceito de sucessão ou transmissão, e o objetivo), acrescentava Perozzi:

"... noipossiamo chiamarlo ora originario ora derivativo, secondo che si prende per criterio il fatto che la proprietà nuova deriva dall'antica o sorge indipendente, oppure il fatto che la proprietà nuova è soggetta o no ai pesi dell'antica".

Daí, a divergência entre a doutrina tradicional e Brinz sobre se o usucapião seria, ou não, modo de aquisição derivada: para a doutrina tradicional, impunha-se a resposta negativa, porque a aquisição era derivada quando havia transmissão ou sucessão, o que inexistia em matéria de usucapião; para Brinz, a solução era diversa, porque ele desvinculava a aquisição derivada do conceito de transmissão lou sucessão) da propriedade, e a ligava ao simples fato de a propriedade do usucapiente continuar onerada pelos ônus reais anteriormente existentes.

Essa desvinculação dos conceitos de aquisição originária e aquisic̣ão derivada do conceito de transmissão ou sucessão de direitos foi impiedosamente atacada por eminentes civilistas, cujos argumentos mantiveram a doutrina tradicional aceita pela quase totalidade dos autores. Nesse ataque, destacaram-se Czihlarz e Scialoja.

Czihlarz (Commentario alle Pandette di Deferico Glück, libro XLI, trad. Perozzi, p. 27-9, Milano, 1905), examinando a tese de Brinz com referência ao usucapião, depois de observar que a circunstância dé o usucapiente poder adquirir a propriedade da coisa cum onere não era decisiva para distinguir a aquisição originária da derivada, pois 
o mesmo ocorre em casos de aquisição inequivocamente originária (como a ocupação de coisa abandonda), salienta, em última análise, que esse critério acabaria com a importância prática da distinção entre aquisição originária e aquisição derivada, importância prática esta que

"sta in ciò, che colui il quale si fonda sopra un modo derivativo, deve addurre e, se è necessario, provare i fatti, che produssero il diritto dell'autore (il diritto originario); mentre una tale necessità nell'acquisto originario locupazione di una coisa derelitta), nei quali viene in questione il diritto di in predecessore, I'esistenza di questo diritto non è mai, come vedremo, uno di quei fattiche si devono provare per sostenere l'azione".

E Scialoja (Teoria della Proprietà nel Diritto Romano, II, n. 11, p. 15 e segs., Roma, 1931), após dizer que a distinção não é romana, mas moderna, e que se baseia no fato de que os modos de aquisição originários são aqueles "per i quali il diritto acquistato non ha suo fondamento nel diritto precedente e derivativi invece quelli, in cui il fondamento del nuovo diritto si ha nel diritto precedente", observa que "il concetto della distinzione, cosi esposto, è semplicissimo" e que "la confusione deriva dal fatto che alcuni autori hanno spinto lo sguardo sopra alcune consequenze normali dell'una o dell'altra categoria ed hano ritenute caratteristiche queste consequenze, mentre il realtà non sono tali'. E, depois de demonstrar que o fato de a coisa por ser adquirida cum onere não pode distinguir a aquisição originária da aquisição derivada, pois isso ocorre com a ocupação de res derelicta, que é, inequivocamente, modo de aquisição originária le a permanência do ônus resulta não da natureza do direito de propriedade do antigo dono, mas de direitos reais limitados existentes em favor de terceiros, e oponíveis inclusive àquele), acrescenta, com relação ao usucapião e à tese de Brinz:

"Il non credo neppure che sipossa ripetere quello che dice il Perozzi in una nota della citada traduzione dell'opera dello Czihlarz, che cioè in questa materia tutto dipenda dal diverso modo di sentire. Se assumiamo, dice il Perozzi, a criteri di distinzione una data considerazione, I'usucapione non sarà modo di acquisto derivato; se invece assumiamo come criterio il contenuto del diritto che si acquista, potremo dire che è un modo derivato. A me non pare; se in molti caso siamo padroni di creare un dato concetto come meglio cipare, in questo non è cosi. Per fare la distinzione fra modi di acquisto originari e derivativi noi partiamo da capisaldi, dicendo, per esempio, che l'occupazione è un modo originario e la tradizione un modo derivativo. Stabiliti questi punti fissi, dobbiamo esaminare le caracteristiche essenziali di questi termini di partenza; ma, nel fare questo esme, nom possiamo abbandonare quei punti fissi, per passare ad altri caratteri. Se il Brinz avesse voluto esser logico, avendo classificato tra i modi di acquisto derivativi l'usucapione, avrebbe dovuto per la stessa ragione classificare tra questi anche l'occupazione, cosa evidentemente assurda.

!o ritengo pertanto che tutta la distinzione deimodidiacquisto in oriyinari e derivativi debba ridursi a quel semplicissimo concetto che abbiamo espoto. Ma è da notare che questo concetto si puo tradurre in un'altra formula della tecnica giuridica, che cioè nei modi diacquisto derivativi vi è sucessione nel senso tecnico-giuridico della parola, mentre nei modi originari non c'è successione". 
Ao lúcido espírito de Scialoja não escapou o fato de que os poucos autores que entendiam que o usucapião era modo de aquisição derivada, só o faziam porque não distinguiam a aquisição originária da derivada com base no critério da ocorrência, ou não, da sucessão (transmissão), mas, sim, com fundamento em outro critério, independente da idéia de sucessão: o do conteúdo do direito que se adquire.

Com efeito, a não ser que se acolhesse a esdrúxula tese de que até o abandono (derelectio) seria uma traditio in incertam personam (tradição a pessoa incerta), não seria possivel sustentar-se que, por meio do usucapião, há transmissão da propriedade do transmitente ao adquirente. Percebeu-o Lacerda de Almeida. Este notável civilista pátrio, no segundo volume de seu Direito das Cousas, p. 121-2, nota 15, invocando Brinz, enquadrou o usucapião entre os modos de aquisição derivada; mais tarde, em 1915, no livro Sucessões, § 2, p. 16, nota 2, Rio de Janeiro, conceituando a sucessão (no sentido moderno de transmissãol, reconheceu que ela não existe em se tratando de usucapião:

"Nem toda mutação de sujeito na relação de sujeito e objeto pode chamar-se sucessão. Observa mui judiciosamente Puchta, Inst., § 198, que no caso de usucapião não se pode chamar o usucapiente de sucessor do dono da cousa, pois a usucapião é modo originário (em seu entender) de aquisição. Seja ou não seja modo originário, o que é verdade é que mui diversa é a situação dọ usucapiente da do comprador, cujo direito deriva imediatamente do vendedor. Cfr. Aubry \& Rau, § 175, not."

A passagem de Aubry \& Rau, invocada por Lacerda de Almeida, se encontra no Cours de Droit Civil, tomo II, 5. ed., §175, p. 95 , Paris, 1897, onde, a propósito das "notions générales sur l'acquisition des droits", se lê:

"Une personne succède à une autre, lorsqu'elle recueille ou acquiert, en vertu de la loi ou de la volonté de l'homme, tout ou partie des droits de cette dernière, avec la faculté de les exercer désormais en son proprenon.

La personne qui se trouve investie d'un droit, non comme le tenant d'une autre personne, mais de son propre chef, ne saurait être considérée comme le successeur de celle-ci, bien qu'ils'agisse du même droit, perdu parl'une, et acquis parl'autre. Ainsi, celuiquidevient, par l'effet de l'usucapion, soit de trente ans, soit de dix à vingt ans, propriétaire d'un immeuble, n'est pas le successeur de la personne au préjudice de laquelle s'est accomplie l'usucapion".

Por isso mesmo, Von Thur (Der Allgemeine des Deutschen Bür gerlichen Rechts, zweiter Band, erste Hälfte, § 44, p. 42, München and Leipzig, 1914), que distingue a aquisição originária da derivada conforme haja, ou não, sucessão, salienta que, naquela - e dá como exemplo típico o usucapião - não há sucessão de direitos, mas suplantação ou substituição do anterior pelo posterior:

"Der Erwerb kann originär sein, obbleich ein Recht gleichen Inhaltes bereits für ein anderes Rechtssubjekt bestand; der Erwerb ist trotzdem originär, wenn das jetzige Recht nicht vom früheren obge- 
leitet ist, sondern einen selbständigen Entstehungstatbestand hat. Dan leigt nicht Sukzession vor, sondern ein Aufeinanderfolge von Rechten, welche man Verdrängung oder Ablösung von Rechten nennen kann, je nachden die Entstehung des neuen oder der Wegfall des alten Rechts als das logische Prius erscheint. Verdrängung von Rechten liegt dann vor, wenn das frühere Recht deshalb untergeht, weil sein Fortbestand mit der Existenz des neuen Rechts unvereinbar ist. Der Hauptfall der Unvereibarkeit von Rechten zeight sich bein Eingentum. Das Musterbeispiel der Rechtsverdrängung ist daher die Ersitzung; der Ersitzende gründet seinen Erwerb auf langjährigen Eigenbesitz in Verbindung mit gutem Glauben oder mit Eintragung, §§937, 900, und sthet zum früheren Eigentümem in keinerlei Beziehung. Die primäre Wirkung der Ersitzung ist Eigentumserwerb; daraus ergibt sich, weil zwei Eigentumsrechte an derselben Sache nicht bestehen können, das Erlöschen des Früheren Eigentums. "I A aquisição pode ser originária, mesmo que já exista um direito de igual conteúdo em favor de outro sujeito de direito; a aquisição é, apesar disșo, originária se o direito atual não deriva do anterior, mas tem um fato constitutivo próprio. Não há, então, sucessão, mas uma seqüência de direitos que se pode chamar de suplantação ou substituição de direitos, conforme o nascimento do novo ou a extinção do antigo direito se apresente como o prius lógico. A suplantação ocorre quando o direito anterior se extingue porque sua subsistência seria incompativel com a existência do direito novo. O caso mais importante da inconciliabilidade de direitos se apresenta na propriedade. O exemplo típico de suplantação é o usucapião; o usucapiente funda sua aquisição na posse própria de mụitos anos aliada à boa fé ou à inscrição no registro imobiliário, §ई 937 e 900, e não tem relação alguma com o proprietário anterior. O efeito primário do usucapião é a aquisição da propriedade; e dele decorre a extinção da propriedade anterior, porque duas propriedades não podem coexistir sobre a mesma coisa).

E Carnelluti (Teoria Giuridica della Circolazione, n. 7, p. 20, Padova, 1933) observa que o usucapião (/a precrizione acquisitiva) não corresponde a um fenômeno de circulação jurídica, pela diversidade do fenômeno econômico:

"Non corrisponde, infine, a un fenomeno di circolazione la prescrizione acquisitiva, per la terza ragione dianzi idicata: manca qui invero la reciprocità tra la modificazione delle situazioni giuridiche dei due titolari; perdita del dominio da parte del soggetto passivo e acquisto da parte del soggetto attivo della usucapione non sono termini correlativi ma indipendenti l'uno dall'altro tanto è vero che mentre non è concepibile che il donante o il ven ditore si spogli della proprietà se non a favore del donatario o del compratore, è non solo ammessibile ma ammesso, se non dalla nostra da altre legislazioni, che il proprietario inerte di fronte al possesso altrui perda la proprietà senza che la acquisti il possessore. Si intende che tale diversità di struttura giuridica trova la sua ragione nella diversità del fenomeno economico: certo anche la usucapione determina uno spostamento nella situazione giuridica dei beni ma qui il diritto opera per far affluire i beni non già dalla abbondanza verso il bisogno bensì dall'inerzia verso il lavoro".

E a prova evidente de que o usucapião não é meio de transmis- 
são de direito real reside no fato de que, por ele, pode adquirir-se direito real intransmissível, como o usufruto, o uso ou a habitação. De feito, se alguém desapossa o usufrutuário, e, como possuidor do direito de usufruto, preenche os requisitos para adquirir esse direito por usucapião, o novo direito de usufruto não deriva do anterior, pois este é intransmissivel, mas, porque ele surge originariamente, o direito de usufruto anterior se extingue, e o novo se opõe inclusive ao proprietário.

Por tudo isso é que os autores nacionais ou estrangeiros quando fazem a distinção entre aquisição originária e aquisição derivada com base no critério da ocorrência, ou não, de sucessão (ou transmissão) de direitos, enquadram, necessariamente, o usucapião entre os modos de aquisição originária, por não ser ele modo de transmissão de direitos. Assim, entre muitos outros, Baron (Pandekten, 6. ed., §130, 2, p. 232, Leipzig, 1887), Pagenstecher (Pandekten-Praktikum, $\$ 45$, p. 206, Heidelberg, 1860), Keler (Pandekten, v. 1, 2. ed., § 123, p. 278, Leipzig, 1966), Waechter (Pandekten, v. 2, §141, p. 167, Leipzig, 1881), Puchta (Vorlesung über das heutige römische Recht, v. 1, 6. ed. , § 155, p. 348, Leipzig, 1873), Dernburg (Pandekten, v. 1, t. 1, 6. ed., § 81, p. 183, nota 1, e v. 1, 2, 6. ed., § 201, p. 81, Berlin, 1900), Forster-Eccius (Preussisches Privatrecht, v. 3, 7. ed., § 177, p. 234, Berlin, 1896), Barassi (/stituzioni di Diritto Privato, $\S 57$, v. 7, p. 170 , Milano, 1939), Torrente (Manuale di Diritto Privato, $\S 207$, p. 286, nota 1. Milano 1952), Trabucchi (/stituzioni di Diritto Civile, n. 179, p. 422, 13. ed., Padova, 1962), Callegari (/stituzionidi Diritto Privato, p. 411, Torino, 1960), Dusi (/stituzioni di Diritto Civile, v. 1, 2. ed. , §51, p. 336, Torino, 1930), Venzi (Manuale di Diritto Civile Italiano, 5. ed., n. 305, p. 282, Torino, 1931), Messineo (Manuale di Diritto Civile e Commerciale, v. 1, 7. ed., § 12, p. 103, Milano, 1946), Nicola Stolfi (Diritto Civile, v. 2, 1, n. 211, p. 154, Torino, 1926), Pugliatti (/stituzioni di Diritto Civile, v. 5, La Proprietà, p. 232, Milano, 1938), Pugliese ( La Prescrizione Acquisitiva, 3. ed., n. 26, p. 43, Torino, 1911), Oliveira Ascensão (Direitos Reais, n. 160, p. 337, Lisboa, 1974) e Pires de Lima e Antunes Varela (Código Civil Anotado, v. 3, p. 55, Coimbra, 1972). No Brasil, o mesmo se observa, inclusive entre nossos juristas mais modernos: Pontes de Miranda (Tratado de Direito Privado, t. XI, 3. ed., §1.192, 1, p. 117, Rio de Janeiro, 1971), Serpa Lopes (Curso de Direito Civil, v. 6, n. 331, p. 506, Rio de Janeiro, 1960), Barros Monteiro (Curso de Direito Civil, v. 3, 14. ed., p. 124, São Paulo, 1975), Orlando Gomes (Direitos Reais, 7. ed., n. 115, p. 158, Rio de Janeiro, 1980), Espínola (Posse - Propriedade, Compropriedade ou Condomínio - Direitos autorais, p. 177, Rio de Janeiro, 1956), Silvio Rodrigues (Direito Civil, v. 5, 4. ed., n. 60, p. 103, São Paulo, 1972), Nequete (Da Prescrição Aquisitiva - Usucapião, 3. ed., n. 8, p. 36, Porto Alegre, 1981), Arnoldo Wald (Direito das Coisas, n. 60, p. 126, São Paulo, 1980), Clovis Couto e Silva (Comentários ao Código de Processo Civil, v. 11, n. 179, p. 187, São Paulo, 1977 e Adroaldo Furtado Fabrício (Comentários ao Código de Processo Civil, v. 8, t. 3. n. 437, p. 639, Rio de Janeiro, 1980). Apenas Caio Mário da Silva Pereira (Instituições de Direito Civil, v. 4, 3. ed., n. 305, p. 129, Rio de Janeiro, 1978) sustenta que o usucapião é modo derivado de aquisição, e isso porque segue ele, em verdade, o critério que Brinz usava para 
distinguir a aquisição originária da derivada, critério esse que, como demonstrei acima, não se baseia na existência, ou não, de transmissão, mas, sim, no fato de a coisa ter tido, ou não, anteriormente dono. Com efeito, para Caio Mário, "considera-se originária a aquisição, quando o indivíduo, num dado momento, torna-se dono de uma coisa que jamais esteve sob o senhorio de outrem" (ob. cit. p. 129). E isso não ocorre com o usucapião, embora neste não haja transmissão de propriedade, como bem acentua Pontes de Miranda (Tratado de Direito Privado, t. 11, 3. ed., § 1192, 1, p. 117, Rio de Janeiro, 1971).

"Na usucapião, o fato principal é a posse, suficiente para originariamente se adquirir; não, para se adquirir de alguém. É bem possivel que o novo direito se tenha começado a formar antes que o velho se extinguisse. Chega momento em que esse não mais pode subsistir, suplantado por aquele. Dá-se, então, impossibilidade de coexistência, e não sucessão, ou nascer um do outro.

Nenhum ponto entre os dois marca a continuidade. Nenhuma relação, tão pouco, entre o perdente do direito de propriedade e o usucapiente".

Essa também a doutrina acolhida pelo Supremo Tribunal Federal, como se vê do decidido no RE 9.056, 2. Turma, relator o Ministro Orozimbo Nonato:

"O usucapião é modo originário de aquisição do domínio. A transcrição de sentença, que o declare, visa, apenas, a publicidade, a resguardar a boa fé de terceiros e assegurar a continuidade do registro (vide Serpa Lopes "Tratado dos Registro Públicos" v. IV, p. 100) e o exercicio do ius disponendi. Sua oponibilidade, pois, ao reivindicante independe de registro" (Revista Forense p. 121/77).

Demonstrado, assim, que não há transmissão de propriedade ou de direito real limitado quando se adquire um desses direitos por meio do usucapião, e sendo certo que, pelo artigo 23,1 , da Constituição Federal, ao Estado-membro só compete instituir imposto sobre transmissão de propriedade ou de direitos reais sobre imóveis, exceto os de garantia, e que, segundo o artigo 110 do Código Tributário Nacional, a lei tributária não pode alterar a definição, o conteúdo e o alcance de institutos e conceitos de direito privado, não se admitindo nesse terreno a denominada interpretação econômica, é de concluirse que é vedado às leis estaduais estabelecer a incidência do imposto de transmissão quando o direito real se adquire por intermédio do usucapião.

\section{Bibliografia}

1. ALMEIDA, Lacerda de. Sucessões. Rio de Janeiro, s. ed., s. d. v.

2. Direito das coisas. s. I., s. ed., s. d. v.

3. ASCENSÃO, José de Oliveira. Direitos reais. Lisboa, s. ed., 1974. v.

4. AUBRY \& RAU. Cours de droit civil. 5. ed. Paris, s. ed., 1897. v.

5. BARASSI, Ladovico. Istituzioni di diritto privado. Milano, s. ed., 1939. $v$.

6. BARON. Pandekten. 6. ed. Leipzig, s. ed., 1887. v.

7. BETTI, Emileo. Istituzionididiritto romano. 2. ed., s.I., s. ed., s. d. v. 
8. BRINZ, Aloys von. Possessionis traditi. In: meinen deutchen rechts, s. I., s. ed., 1859. v. Jahrbuch des ge-

9. CALLEGARI, Pera. Istituzioni di diritto privato. Torino, s. ed., 1960. v.

10. CARNELLUTI, Francesco. Teoria giuridica della circolazione. Padova, s. ed., 1933. v.

11. COUTO e SILVA, Clóvis. Comentários ao código de processo civil. São Paulo, s. ed., 1977.v.

12. CZIHLARZ. Comentario alle pandette di Deferico Gluck. Milano, s. ed., 1905. v.

13. DER ALLGEMEINE teil, des deutschen bürgerlicher rechts; erster band. Leipzig, s. ed., 1910.v.

14. DERNBURG, Thomas Tseilerck. Panderken. Berlin, s. ed., 1900. v.

15. DUSI. Istituzioni di diritto civile. 2. ed. Torino, s. ed., 1930. v. 1.

16. ESPINOLA, Eduardo. Posse-propriedade, compropriedade ou condomínio-direitos. Rio de Janeiro, s. ed., 1956.v.

17. FABRICIO, Adroaldo Furtado. Comentários ao Código de processo civil. Rio de Janeiro, s. ed., s.d. v.

18. FALCÃO, Amilcar. Fato gerador da obrigação tributária. 4. ed. São Paulo, Rev. dos Tribunais, 1977.v.

19. FORSTER-ECCIUS. Preussisches privatrecht. 7. ed. Berlin, s. ed., 1896. v. 3

20. GOMES, Orlando. Direitos reais. 7. ed. Rio de Janeiro, Forense, s.d.v.

21. GROTIUS, Hugo. Le droit de la Querre et de la paix. Trad. de P. Pradier-Fodéré. Paris, s. ed., 1867.2v.

22. INTRODUÇÃO ao direito tributário, parte geral. Rio de Janeiro, Edições Financeiras; s. d. v. 10

23. KELER.Pandekten. 2. ed. Leipzig, s. ed., 1881.v.

24. LEHRBUCH der pandekten; erster band. 2. ed. S.N.T.v.

25. LIMA, Pires de \& VARELLA, Antunes. Código civilanotado. Coimbra, S. ed., 1972. v.

26. MESSINEO, Francesco. Manuale di dirrito civile e commerciale; codicie norme complementari. Milano, Giuffrè", 1946.

27. MONTEIRO, Washington de Barros. Curso de direito civil. 14. ed. São Paulo, Saraiva, 1975. v. 3

28. NEQUETE. Da prescrição aquisitiva-Usucapião. 3. ed., 1981 v.

29. NOGUEIRA, Ruy Barbosa. Da interpretação das leis tributárias. São Paulo, Rev. dos Tribunais, 1963. 143p.

30. PAGENSTECHER, Ernest. Pandekten - praktikum zu puchta's pandekten und girtanner's rechtsfallen, mit hi hinnveisung auf die echrbucher von arndts und. Heidelberg, Bangel and Schmitt., 1860. v.

31. PEREIRA, Caio Mario da Silva. Instituições de direito civil. 3. ed. Rio de Janeiro, 1978. v.

32. PONTES DE MIRANDA, Francisco Cavalcanti. Tratado de direito privado. 3. ed. Rio de Janeiro, Borsoi, 1971.v. 1.

33. PUCHTA, Georg Friedrich. Vorlesung über das heutige römische recht. 6. ed. Leipzig, B. Tauchnitz, 1873. v.

34. PUCHTA, Wolfgang Heinrich. Das Institut der schiedsrichter, nach seinem heutigen gebrauche und seiner brauchbarkeit für abkürzung und verminderung der prozesse betrachtet. Erlangen, J.J. Palm und E. Enke, 1823. $1 \mathrm{v}$.

35. PUGLIATTI, Salvatore. Esecuzione forzata e diritto sostenziale. Milano, A. Giuffrè, 1935. v.

36. La proprietà. In: Istituzioni di diritto civile. 
Milano, A. Giuffrè, 1938.v.

37. PUGLIESE, Guiseppe. La prescrizione acquisitiva. 3. ed. Torino, Unione Tipografico - Editrice, 1911.v.

38. REVISTA FORENSE. Rio de Janeiro, Forense, 121, 1977.

39. RODRIGUES, Silvio. Direito Civil. 4. ed. São Paulo, Saraiva, 1972. v.

40. SCIALOJA, Antonio. Teoria della proprietà nel diritto romano. Roma, s. ed., 1931.v.

41. SERPA LOPES, Miguel Maria de. Curso de direito civil. Rio de Janeiro, Freitas Bastos, 1960. v.

42. Tratado de registros públicos. Rio de Janeiro, Freitas Bastos, 19-v.

43. STOLFI, Nicola. Diritto civile. Torino, s. ed., 1926. v.

44. TELES, Inocencio Galvão. Algumas considerações sobre o conceito jurídico de sucessão. Lisboa, s. ed., 1965. v.

45. TORRENTE, Andrea. Manuale di diritto privato. Milano, Dolt A. Giuf frè, 1952. v.

46. TRABUCCHI. Istituzioni di diritto civile. 13. ed. Padova, s. ed., 1962. v.

47. VENZI. Manuale didiritto civile italiano. 5. ed. Torino, s. ed., 1931.v.

48. WAECHTER. Pandekten. Leipzig, s. ed., 1981.v.

49. WALD, Arnoldo. Direito das coisas. São Paulo, Sugestões Literárias, 1980. v. 